\title{
LA LUCHA ANTITERRORISTA A TRAVÉS DE LA PRISIÓN INDEFINIDA. LOS CASOS ESPAÑOL Y ALEMÁN
}

\author{
THE FIGHT AGAINST TERRORISM THROUGH \\ INDEFINITE PRISON. THE SPANISH AND GERMAN \\ CASES
}

Margarita Roig Torres*

\section{Resumen}

La Ley Orgánica (LO) 1 de 2015 introdujo en el Código Penal español la prisión permanente revisable, con un periodo mínimo de cumplimiento de 25 años pero, en delitos graves de terrorismo, puede alcanzar a los 35 años. En estos ilícitos, además, se endurecen las condiciones para conceder la suspensión o acceder al tercer grado y a permisos de salida. El legislador argumenta que la cadena perpetua ha sido avalada por el Tribunal Europeo de Derechos Humanos (TEDH) y que existe en la legislación comparada; sin embargo, la Corte Europea ha establecido requisitos muy estrictos y, en el derecho alemán, que se ha tomado como modelo, el régimen de suspensión es mucho más beneficioso que en España. Desde luego, estas disposiciones sobre terrorismo plantean serias dudas sobre su constitucionalidad.

\section{Palabras claves}

Prisión permanente, cadena perpetua, prisión indefinida, terrorismo, Código Penal español, derecho penal del enemigo, lucha antiterrorista.

\begin{abstract}
The LO 1 of 2015 introduced in the Spanish Penal Code the permanent reviewable prison, with a minimum compliance period of 25 years, but which, in serious crimes of terrorism, can reach 35 years. In these illicit activities, in addition, the conditions for granting the suspension or access to the third degree and exit permits are hardened. The legislature argues that life imprisonment has been endorsed by the European Court of Human Rights (ECHR) and that it exists in comparative legislation; however, the European Court has established very strict requirements and, in German law, which has been taken as a model, the suspension regime is much more beneficial than in Spain. Of course, these provisions on terrorism raise serious doubts about their constitutionality.
\end{abstract}

\section{Keywords}

Permanent prison, life imprisonment, terrorism, Spanish Penal Code, criminal law of the enemy, fight against terrorism.

*Profesora Titular de Derecho penal, Universitat de València (España). 


\section{La prisión permanente revisable para terroristas en el derecho español}

\section{Los homicidios y asesinatos terroristas: objetivo inicial de esta nueva pena.}

La LO 1 de 2015, de reforma al Código Penal español, introdujo de modo novedoso la prisión permanente revisable teniendo en cuenta que el último texto punitivo que reguló la cadena perpetua fue el de 1870, donde además se preveía el indulto a los 30 años. De todas formas, el legislador ha designado esta pena de ese modo singular (Abel, 2015b; Cuerda, 2011; Fernández, 2014; Mir, Gómez y Valiente, 2015; Muñoz, 2012; Ramírez y Rodríguez; Sáez; Sanz, 2016), con el propósito de subrayar el cumplimiento de la principal exigencia establecida por el TEDH, consistente en el carácter revisable y, al mismo tiempo, salvar los posibles reproches de inconstitucionalidad por los plazos tan dilatados de cumplimiento mínimo que se establecen. De hecho, en el texto inicial se hablaba de 'prisión de duración indeterminada revisable', sustituyéndose, más tarde, por el nombre actual que omite esta alusión a la indefinición temporal.

Pues bien, la nueva sanción se incorporó precisamente para los homicidios y asesinatos terroristas. En el Anteproyecto original se introdujo en el artículo 572.2 $\mathrm{CP}$ para '[1] os que perteneciendo, actuando al servicio o colaborando con las organizaciones o grupos terroristas [...] causaran la muerte de una persona'. Fue más tarde cuando el Gobierno, influido sin duda por la opinión pública (Serrano, 2012; Muñoz y García, 2015; Acale, 2016; Cámara y Fernández, 2016), decidió extenderla a numerosos delitos, algunos directamente relacionados con ciertos sucesos mediáticos (como el asesinato que sigue a un delito contra la libertad sexual) y otros posiblemente tomados del derecho comparado (como el genocidio).

En el texto inicial solo se establecía para los homicidios y asesinatos terroristas (art. 572). En cambio, en el Proyecto, se amplió el número de delitos: asesinato, cuando la víctima sea menor de 16 años de edad, o una persona especialmente vulnerable, cuando el hecho siga a un delito contra la libertad sexual, o si el delito lo realiza quien pertenece a un grupo $u$ organización criminal (art. 140); homicidio del Rey, la Reina, el Príncipe o la Princesa de Asturias (art. 485.1); asesinatos reiterados o en serie (art.572.2.1), homicidio del Jefe de un Estado extranjero, $u$ otra persona protegida en un tratado que se halle en España (art. 605.1); determinados genocidios (art. 607.1.1 y 2) y delitos de lesa humanidad (art. 607 bis, apartado 2). Posteriormente, la LO 2 de 2015, que modificó el Código Penal en materia de terrorismo, aplicó de nuevo la prisión permanente a los homicidios terroristas (art. 573 bis), que se habían suprimido en el texto aprobado. Esta ampliación ponía de relieve que no había un grupo claro de infracciones para las que se considerara imprescindible; los únicos ilícitos para los que parecía incuestionable eran los atentados terroristas.

Esta prioridad se tradujo en la regulación del Código Penal, donde se estableció un régimen especialmente severo para la prisión permanente aplicable a esos hechos. Se prevén plazos mayores para acceder al tercer grado y para obtener permisos de salida, la suspensión de la pena requiere que el condenado observe de- 
terminadas condiciones (abandono de la banda, colaboración activa, etc.) y, en los casos de concurrencia de delitos graves relacionados con el terrorismo, el periodo mínimo de cumplimiento se eleva extraordinariamente, de modo que puede alcanzar los 35 años, lo que supone que no se revisará la condena hasta extinguir este tiempo de prisión efectiva.

Como era de esperar, esta normativa generó fuertes críticas -que coincidían en la falta de una auténtica justificación de esta pena-, tanto en el seno de la doctrina, como por parte de organismos oficiales, entre ellos, el Consejo General del Poder Judicial, cuando expresó que en la situación actual, la incorporación de la prisión permanente revisable al catálogo de penas privativas no se justificaba por el incremento numérico de los crímenes para los que se prevé esa sanción. La tasa de homicidios de España es de las más bajas de Europa. Según el Balance de Criminalidad correspondiente al año 2011, elaborado por el Ministerio del Interior, la tasa de criminalidad española (crímenes por cada 1000 habitantes), es de 48,8, cifra que es inferior a la de Francia $(56,4)$, Alemania $(73,8)$, y Reino Unido $(77,7)$, pero superior a la de Italia $(43,8)$ y Portugal $(40,1)$, estas últimas relativas al año 2009. En el capítulo correspondiente a los homicidios dolosos y asesinatos consumados, la tasa por cada 100.000 habitantes correspondiente al año 2011 fue de 0,82, que fue inferior a la habida en el año $2010(0,85)$. Según Eurostat, en el año 2009, la tasa española de homicidios fue del 0,90, ratio esta que es menor a la de los restantes países europeos, con la salvedad de Alemania $(0,86)$ y Austria $(0,51)$. Como se observa, España no destaca, precisamente, por la alta incidencia de los delitos contra la vida humana independiente y, de ahí que la instauración de la prisión permanente revisable no parece que obedezca a la necesidad de poner freno, mediante un mayor grado de disuasión penológica, a una escalada desmesurada de esta clase delitos (Consejo General del Poder Judicial, 2013, p. 43).

Así mismo, el Consejo de Estado entendió que la introducción de la prisión permanente revisable responde a una libre opción de política legislativa que, sin embargo, no ha sido suficientemente justificada en el expediente. La exposición de motivos del Anteproyecto y la Memoria apuntan, como se ha visto, distintos argumentos destinados a justificar la constitucionalidad y hasta la proporcionalidad de la medida, pero en ningún momento se apuntan las razones, motivos, causas o circunstancias por las que se ha entendido que una reforma de esta magnitud resulta necesaria en el momento actual (Consejo de Estado, 2013). También, el Consejo Fiscal:

Llama la atención del Consejo Fiscal que la introducción de cambios tan radicales en institutos penales claves como [...], la introducción de la pena de prisión permanente revisable $[\ldots]$, no aparezcan debidamente explicados en la exposición de motivos, especialmente mediante la explicitación de cuáles son las razones de política criminal que subyacen en estos cambios" (Consejo Fiscal, 2012, p. 8).

$\mathrm{Al}$ respecto, obsérvese: en primer lugar, había cesado en su actividad la banda armada ETA que perpetró el mayor número de atentados en nuestro país. En este sentido, el Consejo General del Poder Judicial (2013) destacó que, durante los últimos años, la operatividad del principal grupo terrorista ha disminuido de manera 
drástica, principalmente por la labor de los Cuerpos y Fuerzas de Seguridad: “[e] llo denota que la lucha antiterrorista puede ser plenamente eficaz mediante la conjunción de una serie de medidas de diversa índole, sin necesidad de introducir la prisión permanente revisable en el Código penal" (p. 44). En consecuencia, afirmaba que "existen opciones político-criminales que garantizan con similar eficacia la seguridad de los bienes jurídicos sin llegar a la condena a perpetuidad" (p. 36).

Por otra parte, esos mismos órganos recordaban que el tiempo máximo de permanencia en prisión ya se había ampliado a 40 años, pensando el legislador en los atentados terroristas, cuando en otros países, como Alemania, ese tope es de 15 años. La nueva sanción se adoptaba sin revisar el sistema general de penas (Juanatey, 2013; Cuello y Mapelli, 2015; Jaén y Perrino, 2015; Tamarit, 2015).

Además, las cifras de delincuencia en España no eran elevadas, en comparación con otros Estados europeos. En realidad, los balances de criminalidad que publica el Ministerio del Interior revelan un descenso generalizado de las infracciones penales en los últimos años: en 2011 (cuando se tramitó el Anteproyecto) se redujeron un 0,5\% respecto al año anterior; en 2012, un 0,7 \%; en 2013, un 4,3\%; en 2014, un 3,6 \%; en 2015, un 1,9 \%; y, en 2016, un 1,4 \% (Gobierno de España, 2015). En la presentación de estos documentos el Ministro destacaba que el índice de infracciones penales en España se mantiene entre los más bajos de la Unión Europea.

De igual forma, el porcentaje de asesinatos, incluyendo los de índole terrorista, es también de los menores de nuestro entorno (Díez-Ripollés, 2006, 2015; García, Díez-Ripollés, Pérez, Benítez y Cerezo, 2010, p. 19 y ss.). Según informaba el propio ministro, la tasa media en la Unión Europea es de 1,00 asesinatos u homicidios consumados por cada 100.000 habitantes, mientras en España es de 0,64 (Unión Europea, 2015).

Pese a esos índices de delincuencia relativamente bajos, el aumento de las penas de prisión, motivado en buena medida por el temor al terrorismo, ha hecho que las prisiones españolas tengan una de las tasas de población reclusa mayores de Europa (García y Díez-Ripollés, 2013), situándose en segundo lugar después del Reino Unido. Además, la duración media de permanencia en la cárcel duplica al menos a la de los países europeos más importantes. El porcentaje de internos es de 147 por cada 100.000 habitantes, mientras que en Alemania, por ejemplo, es de 90 internos (Fischer, 2015).

Por eso, para explicar las modificaciones adoptadas en el Código Penal, en la Exposición de Motivos de la LO 1 de 2015, de 30 de marzo, se dice que "[1]a necesidad de fortalecer la confianza en la Administración de Justicia hace preciso poner a su disposición un sistema legal que garantice resoluciones judiciales previsibles que, además, sean percibidas en la sociedad como justas", lo que, en definitiva, se traduce en un endurecimiento del sistema punitivo.

De hecho, en el Congreso de los Diputados se modificó la argumentación del Anteproyecto y del Proyecto, para justificar esas reformas. Al igual que en esos textos se alude a esa 'necesidad de fortalecer la confianza en la Administración de 
Justicia', pero, en la versión remitida al Senado, se añade: "con esta finalidad, siguiendo el modelo de otros países de nuestro entorno europeo, se introduce la prisión permanente revisable para aquellos delitos de extrema gravedad, en los que los ciudadanos demandaban una pena proporcional al hecho cometido" (Martín, 2012, p. 6). De esta forma, se pone de relieve que la prisión permanente revisable es el instrumento central para conseguir ese objetivo; por lo tanto, es esa demanda ciudadana de rigor o de 'mano dura' frente a determinados delincuentes lo que lleva al legislador a incorporar esta nueva pena y no razones preventivas (Juanatey, 2012, 2016; Abel, 2015a; Cervelló, 2015b; Lascuraín, 2015, pp. 66 y ss.).

Además, en la Exposición de Motivos de la ley de reforma se aducen dos motivos para adoptar la nueva pena: que está prevista en el derecho comparado europeo y que ha sido avalada por el TEDH; sin embargo, al analizar el derecho alemán, que nuestro legislador ha tomado como modelo para regular esta sanción, se comprueba que el régimen de la cadena perpetua es más beneficioso en ese ordenamiento, al menos en lo que hace al régimen de suspensión de la pena. Igualmente, la Corte Europea ha establecido requisitos muy estrictos para que la prisión indefinida sea adecuada al CEDH: en esencia, que se reconozca al penado una expectativa legal y práctica de liberación y que se regule un régimen de revisión que permita valorar los posibles cambios en la vida del interno y sus progresos hacia la resocialización. Por eso, resulta oportuno conocer las exigencias del TEDH frente a la cadena perpetua, así como la regulación de esta pena en Alemania.

\section{La aprobación de la cadena perpetua por el TEDH como justificación de la reforma.}

En la Exposición de Motivos de la LO 1 de 2015, se afirma como fundamento de la prisión permanente que

se trata, en realidad, de un modelo extendido en el Derecho comparado europeo que el Tribunal Europeo de Derechos Humanos ha considerado ajustado a la Convención Europea de Derechos Humanos, que ha declarado que cuando la Ley nacional ofrece la posibilidad de revisión de la condena de duración indeterminada con vistas a su conmutación, remisión, terminación o libertad condicional del penado, esto es suficiente para dar satisfacción al artículo 3 del Convenio (Cfr. SSTEDH 12-2-2008, Kafkaris vs. Chipre; 3-11-2009, Meixner vs. Alemania; 13-11-2014, Bodein vs. Francia; 3-2-2015, caso Hutchinson vs. Reino Unido) (Roig, 2013, 2016).

No obstante, entre estas resoluciones se omite la sentencia dictada por la Gran Sala del TEDH (Vinter vs. United Kingdom, 2013), en la que se declaró que la cadena perpetua impuesta a los recurrentes era una pena inhumana o degradante prohibida por el artículo $3 \mathrm{CEDH}$, puesto que la normativa de Inglaterra y Gales no prevé un régimen suficiente de revisión en el caso concreto de la cadena perpetua obligatoria por asesinato, cuando el Tribunal acuerda el cumplimiento íntegro. Paradójicamente, en la sentencia posterior de la Sección 4 (Hutchinson vs. Reino Unido, 2015), que se cita expresamente en la Exposición de Motivos, se llegó a una conclusión contraria, pese a que no se había producido ningún cambio legal. En la primera, se parte de los argumentos manejados en las resoluciones mencionadas 
por el legislador español y a partir de ellos se estima el recurso, mientras que en la última se llega a la solución opuesta.

\section{STEDH -Gran Sala- de 9 de julio de 2013.}

En el caso Vinter vs. United Kingdom (TEDH, 2013), los recurrentes eran ciudadanos británicos que habían sido condenados a cadena perpetua por asesinato con una orden de cumplimiento de por vida (whole life order) y alegaban que esta pena era contraria al artículo $3 \mathrm{CEDH}$ que prohíbe las penas inhumanas o degradantes.

Como consecuencia de esa demanda, el TEDH analizó la legislación de Inglaterra y Gales. En ella se prevén varias modalidades de prisión indefinida: la cadena perpetua por la comisión de segundos delitos tasados (Life sentence for second listed ofender), la cadena perpetua para la protección pública para delitos graves (Imprisonment for public protection for serious offences), ambas para delitos violentos o sexuales, y la cadena perpetua obligatoria para los delitos de asesinato (Mandatory life sentence). Las dos primeras no son obligatorias, sino que el Tribunal puede decidir no imponerlas si no lo considera necesario. Además, en caso de acordarlas, debe fijar el periodo mínimo de cumplimiento (tariff) que es el tiempo que el sujeto debe permanecer en prisión, antes de que se revise su condena para valorar su excarcelación bajo supervisión dado que, en esa legislación, si se libera al condenado, se le somete a control durante toda su vida.

Pues bien, en la última pena de cadena perpetua (la preceptiva por asesinato), antes se preveía también la obligación de revisar la condena a los 25 años; sin embargo, a raíz de ciertos cambios legislativos se omitió esta norma; una disposición del Ministerio del Interior de 10 de noviembre 1997 establecía que podría reducirse el periodo mínimo de cumplimiento en circunstancias excepcionales como, por ejemplo, cuando hubiese un progreso extraordinario por parte del prisionero. Esta posibilidad la debía tener en cuenta el Ministro a los 25 años, en los casos de presos con una orden de internamiento para toda la vida; sin embargo, la Criminal Justice Act 2003 no contempló esta revisión. De manera que, en algunos casos, el juez ha de fijar un periodo mínimo de cumplimiento (que oscila entre 30 y 12 años), pero, en otros, se ordena el internamiento de por vida. Entre estos supuestos se encuentra el asesinato cometido con fines políticos, donde tiene encaje el terrorismo. Y, cuando se acuerda esta prisión indefinida, ya no se contempla ese deber de revisión. Esto fue lo que llevó al TEDH a declarar que esta pena era contraria al artículo 3 CEDH.

La Gran Sala señala respecto a la cadena perpetua que "[1]a imposición de dicha pena a un delincuente adulto no es en sí misma contraria o incompatible con el artículo 3, o cualquier otro artículo del Convenio". Ahora bien, añade que

el artículo 3 debe interpretarse, en el contexto de una cadena perpetua, como una exigencia de revisibilidad de la sentencia, en el sentido de permitir a las autoridades nacionales tener en cuenta si hubo algún cambio en la vida del prisionero tan importante, y si hubo progresos hacia la rehabilitación de tal entidad, en el curso del cumplimiento de la condena, que impidan justificar el mantenimiento de la privación de libertad en razones penológicas legítimas. 
Además, tras reconocer la soberanía de cada Estado para fijar el momento de revisión, afirma que

la Corte también observa que en derecho comparado e internacional se muestra un claro apoyo a un mecanismo específico que garantice una revisión no después de 25 años tras la imposición de una cadena perpetua, con exámenes periódicos a partir de entonces.

\section{Asimismo, señala que}

un preso sometido a (cadena) perpetua tiene derecho a conocer, al inicio de su condena, lo que debe hacer para ser considerado apto para la liberación y bajo qué condiciones reclamarlo, lo que incluye saber cuándo podrá solicitar una revisión de su sentencia.

En esencia, subraya "que una sentencia condenatoria a cadena perpetua sólo es compatible con el artículo 3 si ofrece al preso tanto una perspectiva de liberación como una posibilidad de revisión de su condena". Atendiendo a estos argumentos, la Corte concluyó que la cadena perpetua obligatoria para los delitos de asesinato, prevista en Inglaterra y Gales era una pena inhumana o degradante prohibida por el artículo $3 \mathrm{CEDH}$, en la medida en que no se establecía la necesidad de revisión cuando se decretaba para toda la vida.

\section{STEDH -Sección $4^{a}$ - de 3 de febrero de 2015.}

Posteriormente, en la STEDH -Sección $4^{\mathrm{a}}$ - del caso Hutchinson vs. United Kingdom (2013), la Corte se vuelve a referir a la cadena perpetua obligatoria por asesinato en la legislación británica, cuando se impone una orden para toda la vida. Ahora bien, en esta ocasión niega que dicha pena infrinja el artículo $3 \mathrm{CEDH}$, contradiciendo la resolución anterior.

El TEDH insiste en que la condena ha de ser legal y efectivamente revisable; sin embargo, después del caso Vinter, el Tribunal de Apelación de Inglaterra y Gales se pronunció sobre esa modalidad de cadena perpetua en la sentencia de 18 de febrero de 2014 (R. vs. Ian McLoughlin; R. vs. Lee William Newell). Y esto determinó que la Corte diera una respuesta contraria a la anterior, al tratar de respetar la soberanía de los órganos judiciales nacionales.

En las dos sentencias de 2013 y de 2015, el TEDH debía resolver si el artículo 30 de la Crime (Sentences) Act 1997, que atribuye al Secretario de Estado la potestad de liberar a cualquier prisionero por razones humanitarias, era suficiente o no para estimar que la cadena perpetua obligatoria por asesinato con una orden de por vida es revisable; en efecto:

Artículo 30: 1) El Secretario de Estado podrá, en cualquier momento, dejar a un condenado a cadena perpetua en libertad condicional si está convencido de que existen circunstancias excepcionales que justifiquen la libertad por razones humanitarias. 2) Antes de liberar a un prisionero bajo el apartado 1 anterior, el Secretario de Estado deberá consultar al equipo de libertad condicional, a menos que las circunstancias sean tales que la consulta sea impracticable. 
Esta norma se complementa con la Circular del Servicio de Prisiones $n^{\circ} 4700$ de 2010 (Prison Service Order 4700), publicada bajo el título Manual del condenado a cadena perpetua (The Indeterminate Sentence Manual). Este texto, en su Capítulo 12, recoge los criterios orientativos para excarcelar por motivos compasivos:

[q]ue el preso sufra una enfermedad terminal y sea probable que la muerte se produzca muy pronto (aunque no hay límites temporales establecidos, tres meses pueden considerarse un margen adecuado para que la solicitud se incluya en la Sección de Casos de la Protección Pública [PPCS]), o el interno esté postrado o incapacitado, por ejemplo, parapléjico o con derrame cerebral grave, y que el riesgo de reincidencia (en particular de carácter sexual o violento) sea mínimo; y que prolongar la prisión reduciría la esperanza de vida del preso; y que existan medios adecuados para el cuidado del prisionero y el tratamiento fuera de la cárcel; y que la liberación temprana entrañe algún beneficio significativo para el preso o su familia.

En el caso Vinter (2014), esta disposición se consideró insuficiente; sin embargo, el Tribunal de Apelación inglés interpretó de un modo amplio esa norma, para indicar que el Secretario de Estado debe excarcelar al condenado siempre que, por cualquier motivo, la continuación del internamiento convierta la pena en inhumana o degradante. En realidad, esto mismo ya lo habían dicho otros tribunales británicos antes del caso Vinter (R. vs. David Francis Bieber, 2008; y R. vs. Oakes and others, 2012), pero, pese a ello el TEDH, entendió que ese precepto no garantizaba la revisión y la esperanza de excarcelación.

En cambio, como la sentencia inglesa era posterior a la de la Corte de 2013, y el Tribunal de Apelación inglés destacó la necesidad de interpretar su legislación conforme al CEDH, en el caso Hutchinson, el TEDH declaró que la cadena perpetua obligatoria con una orden de por vida no viola el artículo 3 CEDH y, en definitiva, dio por válida una pena que carece de un plazo concreto de revisión.

A partir de estas resoluciones se suscita la duda de si la prisión permanente revisable cumple las exigencias establecidas por el TEDH consistentes en garantizar al penado una expectativa legal y práctica de liberación y si se establece un régimen de revisión que permita valorar los progresos del penado hacia la resocialización. Estos interrogantes se plantean, principalmente, para las condenas con los periodos de ejecución más largos, de hasta 28 o 35 años, previstos para los delitos de terrorismo, puesto que la Corte marca como límite para la revisión 25 años, aunque reconoce que no es competente para concretar este extremo.

\section{Declaraciones del Tribunal Constitucional sobre la cadena perpetua.}

En España, el Tribunal Constitucional se ha pronunciado sobre la cadena perpetua en casos de extradición, cuando la solicita un país para aplicar esta sanción o para juzgar por un delito castigado con ella (Roig, 2016). En la sentencia 181, por ejemplo, señaló que "la imposición de una pena de cadena perpetua puede vulnerar la prohibición de penas inhumanas o degradantes del artículo 15 CE" (Tribunal Constitucional, 2004). 
No obstante, el propio Tribunal ha considerado garantía suficiente para conceder la extradición, de acuerdo con la doctrina del TEDH, que en caso de imponerse dicha pena su ejecución "no sea indefectiblemente de por vida", es decir, precisa que sea revisable (Tribunal Constitucional, sentencia 148, 2004). Por lo tanto, se debe reconocer al extraditado "la posibilidad de acogerse a medidas de revisión de pena o aplicación de medidas de clemencia con vistas a la no ejecución de la pena" (Tribunal Constitucional, sentencia 351, 2006) y, en este sentido, a los efectos de otorgar la extradición, basta que la condena sea revisable. Además, esta condición la plantea en sentido amplio, cuando alude a medidas de clemencia, en las que podría tener cabida el indulto.

Por otra parte, destaca que en la extradición el país requirente no está sometido a nuestra Constitución, aunque las autoridades no deben reconocer resoluciones que impliquen una vulneración de los derechos fundamentales. Aunque los derechos fundamentales y libertades públicas que la Constitución garantiza sólo alcanzan plena eficacia allí donde rige el ejercicio de la soberanía española, nuestras autoridades públicas, incluidos los Jueces y Tribunales, no pueden reconocer ni recibir resoluciones dictadas por autoridades extranjeras que supongan vulneración de los derechos fundamentales y libertades públicas garantizados constitucionalmente a los españoles o, en su caso, a los españoles y extranjeros (Tribunal Constitucional, sentencia 43,1986). También:

[s]i los órganos judiciales españoles, siendo conocedores de la eventual vulneración de los derechos fundamentales del recurrente en el país de destino, no la evitan con los medios de que disponen, a dichos órganos habrá de serles imputables esa eventual vulneración de los derechos fundamentales del reclamado (Tribunal Constitucional, sentencia 32, 2003).

Pero el artículo 25.2 CE no contiene un derecho de esta naturaleza sino un mandato dirigido al legislador español que no vincula a otros Estados. De manera que en los recursos contra solicitudes de extradición en los que se ha alegado que la prisión perpetua podría violar dicho precepto, el Tribunal Constitucional ha rechazado que esa norma sirva de base por sí sola para fundar la pretensión de amparo al no recoger un derecho fundamental (Ortiz de Urbina, 2012, p. 8).

\section{La prisión permanente revisable aplicable a terroristas.}

\section{Especialidades para delitos de terrorismo.}

El artículo 33.2 CP califica la prisión permanente revisable como pena grave y el artículo $35 \mathrm{CP}$ la incluye entre las penas privativas de libertad, al hilo de lo cual cabe recordar que, en el Anteproyecto original, no figuraba en estos preceptos (González, 2013); sin embargo, no cuenta con una normativa propia entre estas sanciones. En realidad, lo que se regula es la suspensión de la ejecución, además de algunas normas especiales de carácter penitenciario, relativas al acceso al tercer grado y permisos penitenciarios, y ciertos aspectos en cuanto a la determinación de pena (Roig, 2016). 
El artículo $92 \mathrm{CP}$, en el apartado 1, establece los siguientes requisitos para suspender la prisión permanente revisable: que el penado haya cumplido 25 años, salvo lo dispuesto en el artículo 78 bis, que esté clasificado en tercer grado, y, que exista un pronóstico favorable de reinserción social (Landa y Serrano, 2013; Roig, 2014). Para dicho pronóstico, el Tribunal tendrá en cuenta la personalidad del penado, sus antecedentes, las circunstancias del delito cometido, los bienes que podrían verse afectados por una reiteración delictiva, su conducta durante el cumplimiento de la pena, sus circunstancias familiares y sociales, y los efectos que quepa esperar de la propia suspensión de la ejecución y del cumplimiento de las medidas que fueren impuestas. A tales efectos, valorará los informes de evolución remitidos por el centro penitenciario y por aquellos especialistas que el propio Tribunal determine (art. $92.1 \mathrm{c}$ ).

Pues bien, en el apartado 2 se añaden condiciones específicas para los delitos de terrorismo: si se tratase de delitos referentes a organizaciones y grupos terroristas y delitos de terrorismo del Capítulo VII del Título XXII del Libro II de este Código (crítico, Álvarez y Sanz, 2012). Esta norma se aplicará cuando una persona que pertenece, actúa, sirve o colabora a / con un grupo u organización terrorista cometa un delito castigado con prisión permanente revisable (asesinato -art. 140.1. $3^{\circ} \mathrm{CP}$-, homicidio del Rey o la Reina o de los Príncipes de Asturias -art. 485.1 CP-, etc.) o si realiza varios y alguno de ellos conlleva esa pena, siempre que no rija el artículo 78 bis CP.

Esos requisitos son semejantes a los previstos para la libertad condicional ordinaria en el artículo 90 CP (Díez-Ripollés, 2013): que el penado muestre signos inequívocos de haber abandonado los fines y los medios de la actividad terrorista, y, que haya colaborado activamente con las autoridades. Esta colaboración podrá darse, bien para impedir la producción de otros delitos por parte de la organización o grupo terrorista, para atenuar los efectos de su delito, para la identificación, captura y procesamiento de responsables de delitos terroristas, para obtener pruebas o para impedir la actuación o el desarrollo de las organizaciones o asociaciones a las que haya pertenecido o con las que haya colaborado. Estas acciones pueden acreditarse mediante una declaración expresa de repudio de sus actividades delictivas y de abandono de la violencia y una petición expresa de perdón a las víctimas de su delito, o mediante informes técnicos.

Estos presupuestos merecen críticas semejantes a las que hasta ahora planteaba su exigencia en la libertad condicional regulada en el artículo 90 CP: se vincula la suspensión de la pena al abandono de la actividad terrorista y se prevé como vía para acreditarlo una declaración de repudio que roza con la esfera de la moral, en la que el derecho penal no debe intervenir. A ello se suman los riesgos que esas exigencias pueden suponer para el reo, ante posibles represalias de la banda.

Ahora bien, en la prisión permanente revisable estas condiciones conllevan una carga añadida, puesto que la cooperación requerida se dificulta sustancialmente después de un periodo de prisión tan extenso, que en muchos casos impide al interno esa actuación positiva y puede suponer un obstáculo para obtener la sus- 
pensión de la pena. Por otra parte, el artículo 36 CP prevé normas específicas para la clasificación en tercer grado y la concesión de permisos de salida: con carácter general, dispone que el acceso al tercer grado no se conceda a los condenados a prisión permanente revisable hasta cumplir 15 años, pero ese término será de 20 años en los delitos de terrorismo. Asimismo, el penado no podrá disfrutar de permisos de salida hasta los 8 años, y este término se aumenta a 12 años en esos delitos.

Además, el artículo 78 bis CP aplica plazos más largos cuando se condena por varios delitos, si alguno de ellos está castigado con prisión permanente revisable y el resto suman más de 5 años. El periodo mínimo de cumplimiento es de 25 o 30 años según los casos; sin embargo, en los delitos de terrorismo y delincuencia organizada ese tiempo se eleva a 28 y 35 años. Igualmente, el plazo para obtener el tercer grado oscila entre 18 y 22 años, pero se incrementa a 24 y 32 años en esas formas de criminalidad.

Asimismo, en materia de determinación de pena, el artículo 70.4 CP establece una regla específica, disponiendo que la pena inferior en grado a la prisión permanente es la pena de prisión de 20 a 30 años. Esto supone que, en caso de quedar el delito en grado de tentativa, si se enjuicia al cómplice, o si concurre alguna de las causas legalmente previstas para esa rebaja, no procederá esta sanción sino la prisión con la extensión indicada. En cambio, de la normativa no se deduce la exclusión de esta pena para los inductores y cooperadores necesarios, a los que en principio les corresponde igual pena que al autor al tenor del artículo $28.2 \mathrm{CP}$.

En todo caso, si se concede la suspensión de la pena, el artículo 92 CP fija un plazo de suspensión de entre 5 y 10 años; en cambio, si se deniega, el Tribunal deberá revisar la condena al menos cada 2 años. De todos modos, después de cumplir 28 o 35 años es difícil que la situación del condenado por terrorismo cambie en solo 2 años. Con estas revisiones periódicas el legislador trata de garantizar la adecuación al CEDH y la constitucionalidad de la pena.

\section{Homicidios y asesinatos terroristas.}

La prisión permanente revisable se creó pensando en los homicidios y asesinatos terroristas. El Anteproyecto de Ley Orgánica 1 de 2015, reformó el apartado 2 del artículo 572 dándole la siguiente redacción: " 2 . Los que perteneciendo, actuando al servicio o colaborando con las organizaciones o grupos terroristas atentaren contra las personas, incurrirán: 1 . En la pena de prisión de duración indeterminada revisable si causaran la muerte de una persona". Posteriormente, en la versión de once de octubre de 2012, se mantuvo esa misma disposición pero modificándose la denominación de la nueva pena, que pasaba a llamarse 'prisión permanente revisable', redacción que se mantuvo también en el Proyecto de 20 de septiembre de 2015.

En cambio, en el texto remitido al Senado (Cortes Generales, 2015), se suprime esa disposición y solo se prevé esta sanción para los asesinatos terroristas. De acuerdo con el artículo 140 CP, “[e]l asesinato será castigado con pena de prisión 
permanente revisable cuando concurra alguna de las siguientes circunstancias: [...] 3. ${ }^{a}$ Que el delito se hubiera cometido por quien perteneciere a un grupo $\mathrm{u}$ organización criminal".

Fue más tarde, con la Ley Orgánica 2 de 2015, cuando de nuevo se castigó el homicidio terrorista con prisión permanente revisable. En realidad, el artículo 573 bis $\mathrm{CP}$, dispone:

[1]os delitos de terrorismo a los que se refiere el apartado 1 del artículo anterior serán castigados con las siguientes penas: $1 .{ }^{a}$ Con la de prisión por el tiempo máximo previsto en este Código si se causara la muerte de una persona.

La redacción no puede ser más confusa, pues no se dice expresamente que se aplique esa pena y, teniendo en cuenta que el artículo $35 \mathrm{CP}$ clasifica la prisión permanente revisable como una pena privativa de libertad distinta de la prisión, podría interpretarse ese precepto en sentido estricto entendiendo que la sanción procedente es la prisión. Pero de la tramitación parlamentaria se desprende que el propósito de los impulsores de la reforma era "que a los delitos de terrorismo con resultado de muerte les sea siempre aplicable la máxima pena privativa de libertad recogida en el Código penal" (Congreso de los Diputados, 2015, p. 88). Esta interpretación que identifica la pena del número $1^{\circ}$ del artículo 573 bis $\mathrm{CP}$ con la prisión permanente revisable es absolutamente uniforme en la doctrina (Cano, 2015; Castellví, 2015a, 2015b; Queralt, 2015; Vázquez, 2015; Manzanares, 2015; Muñoz, 2015; Cuerda, 2016; García, 2016; Lamarca, 2016; Olmedo, 2016; Orts y González, 2016; Rueda, 2016).

En realidad, esa redacción ambigua fue fruto del Pacto contra el yihadismo entre los dos grupos parlamentarios mayoritarios (PP y PSOE), buscando una terminología que soslayase la referencia a la prisión permanente revisable a la que el último partido había votado en contra (García, 2012).

No obstante, el problema de fondo que plantea esta norma es la equiparación penológica entre el homicidio y el asesinato, cuando se califican como delitos de terrorismo según el artículo $573.1 \mathrm{CP}$, por cuanto se aplica la misma pena de prisión permanente a dos ilícitos distintos, que fuera de este contexto conllevan sanciones diferentes, conculcándose la debida proporcionalidad entre la gravedad del hecho y de la culpabilidad y la respuesta penal. Por otra parte, no se precisa si el número $1^{\circ}$ del artículo 573 bis $\mathrm{CP}$ abarca los homicidios y asesinatos terroristas imprudentes. No obstante, haciendo una interpretación estricta, acorde con el artículo $12 \mathrm{CP}$, donde se dice que las acciones y omisiones imprudentes solo se castigarán cuando expresamente lo disponga la ley, y con el principio de intervención mínima, creo que ese precepto debe ceñirse a las muertes dolosas.

En conclusión, los homicidios y asesinatos terroristas se castigan con prisión permanente revisable $y$, si son varios, entra en juego el artículo 78 bis $\mathrm{CP}$, en cuanto al periodo mínimo de cumplimiento y el acceso al tercer grado. En esta disposición no se dice nada en cuanto a los permisos de salida, por lo que entiendo que debe estarse a la regla general fijada para los delitos de terrorismo en el artículo $36.1 \mathrm{CP}$, donde se dispone que no podrán otorgarse hasta que el penado haya 
cumplido un mínimo de 12 años. Hay que tener en cuenta que el Tribunal Constitucional ha declarado que la posibilidad de conceder dichos permisos se conecta con el fin esencial de reeducación y reinserción social del artículo 25.2 CE (Tribunal Constitucional, sentencia 115, 2003).

\section{Valoración de estas normas desde el prisma constitucional.}

A la vista de estos antecedentes cabe cuestionar la adecuación del régimen de la prisión permanente revisable a la Constitución, sobre todo, en lo que hace a la normativa prevista para los delitos de terrorismo. La problemática se centra, principalmente, en el periodo mínimo de cumplimiento que en estos casos puede alcanzar los 35 años, muy por encima del plazo normal de la mayoría de países europeos y de los 25 años indicados por el TEDH.

En primer lugar, la nueva pena suscita dudas desde el punto de vista del principio de resocialización del artículo 25.2 CE (De la Cuesta, 2009; Cuerda, 2012; Díaz-Maroto y Villarejo, 2012; Terradillos, 2012; Urruela, 2012; Acale, 2013; Cancio, 2013; Daunis, 2013; Ríos, 2013, 2014; Serrano, 2013; Hidalgo, 2013; Juanatey, 2013; Marín de Espinosa y González, 2013 Fernández, 2014; Fuentes, 2014; García, 2014; Grupo de Estudios de Política Criminal, 2015; Bonet, 2015; Carbonell, 2015; Cervelló, 2015a, 2015b). De acuerdo con las normas previstas para los concursos de delitos relacionados con el terrorismo, una persona puede tardar 32 años en acceder al tercer grado y 35 años hasta que se realice la primera revisión. Es decir, si ha ingresado con 18 años, cosa improbable por la tardanza de los procesos, no podrá salir en libertad antes de cumplir 53 años. Me parece dudoso que con un horizonte tan lejano se cumplan los requisitos marcados por el TEDH, consistentes en garantizar al interno una 'expectativa legal y práctica de liberación' y en regular un régimen que permita 'valorar los posibles cambios en la vida del penado y sus progresos hacia la resocialización'. Además, es difícil que una pena tan extensa pueda orientarse a la resocialización, teniendo presente que el sujeto es consciente del elevado número de años de reclusión que ha de cumplir de forma efectiva, de manera que es muy posible que su disposición a colaborar de cara a su reinserción social disminuya (Martín, 2012; Jaén, 2013).

Pero, el principio que de verdad flaquea es el de proporcionalidad: en el texto del Proyecto se argumenta que, con la introducción de esta pena, se quiere aumentar la confianza social en la Administración de Justicia. Por consiguiente, se busca mejorar la opinión de los ciudadanos respecto al sistema judicial, proporcionándoles las sentencias que desean, lo que se traduce en la imposición de penas más duras. Con todo, esa opinión pública está influida por los medios de comunicación y no se corresponde con la tasa real de delincuencia. En la medida, pues, en que en la adopción de este nuevo castigo han influido intereses ajenos a la tutela de bienes jurídicos esenciales, puede resultar vulnerado el principio de intervención mínima.

Precisamente, el TEDH (Stafford vs. United Kingdom, 2002), rechazó el argumento del Gobierno de mantener a una persona en prisión atendiendo a la opinión pública y afirmó que la confianza en el sistema de justicia penal no puede legitimar 
la continuación del encarcelamiento de un prisionero que ha cumplido el tiempo mínimo si ya no es peligroso para la comunidad. Es decir, la opinión pública y la alarma social no son razones legítimas para mantener a una persona privada de libertad.

Además, la prisión permanente revisable se establece siempre con carácter preceptivo, sin dejarle al juzgador valorar las circunstancias del caso (Del Carpio, 2013) y se aplica en supuestos de entidad dispar, como en el indicado de homicidio o asesinato terroristas; lo mismo sucede con el asesinato que sigue a cualquier delito contra la libertad sexual (art. 140.1. $2^{\mathrm{a}} \mathrm{CP}$ ) y el genocidio acompañado de muerte, agresión sexual o lesiones (art. $607 \mathrm{CP}$ ).

En conclusión, la regulación excepcional establecida para los delitos de terrorismo responde a la demanda represiva de un sector de la sociedad, como efectivamente reconoce la Exposición de Motivos de la LO 1 de 2015. Además, persigue la denominada 'inocuización', es decir, el aislamiento del sujeto durante el mayor tiempo posible para que no delinca. Se parte, pues, de un fin de prevención especial que, como se verá, el Tribunal Constitucional alemán negó como fundamento de la prisión indefinida, por no ser fiables los pronósticos de peligrosidad y por el bajo porcentaje de reincidencia en los delitos de asesinato. Por ende, esas disposiciones que regulan la prisión permanente revisable para los delitos de terrorismo resultan injustificadas desde el punto de vista del principio de proporcionalidad, en tanto no buscan solo proteger bienes jurídicos, sino también satisfacer a un sector de la población, pese a que su percepción de la delincuencia no se corresponde con las tasas de criminalidad real.

\section{El derecho alemán como modelo de la prisión permanente revisable}

\section{Regulación legal de la cadena perpetua.}

En el ordenamiento alemán el § 38 StGB (Código Penal) dispone: “1. La pena privativa de libertad es temporal, salvo que la ley imponga cadena perpetua. 2 . La extensión máxima de la pena privativa de libertad temporal es 15 años, su extensión mínima es un mes". Por lo tanto, en Alemania la cadena perpetua (lebenslange Freiheitsstrafe) se configura como una excepción a la privación de libertad temporal, de manera que el legislador la establece con carácter indefinido solo en supuestos extraordinarios (Fischer, 2006, 2012, 2015; Stree y Kinzig, 2006; Tröndle y Kühl, 2011).

Además, no se prevé siempre como sanción obligatoria, sino que, en algunos casos, se permite al Tribunal aplicar en su lugar una pena de prisión. En concreto, es preceptiva en el asesinato y el genocidio con muertes:

$\S 220$ a StGB (Genocidio): 1. Quien con intención de destruir entera o parcialmente un determinado grupo nacional, racial, religioso o étnico: $1^{\circ}$, mate a miembros del grupo, $2^{\circ}$, cause a miembros del grupo graves daños físicos o mentales, en especial del tipo del artículo $226,3^{\circ}$, someta al grupo a condiciones de vida apropiadas para provocar total o parcialmente su destrucción física, $4^{\circ}$, imponga medidas que impi- 
dan los nacimientos dentro del grupo, o $5^{\circ}$, traslade a la fuerza niños de un grupo a otro, será castigado con cadena perpetua. 2. En los casos menos graves de los apartados 2 a 5 del párrafo anterior, cabe no imponer cadena perpetua, si bien la pena privativa de libertad no será inferior a 5 años.

En cambio, es potestativa en delitos como el homicidio grave, alta traición; en efecto:

§ 81 StGB (Alta traición): 1. Quien se compromete, con violencia o a través de la amenaza de violencia, $1^{\circ}$, a perjudicar la existencia de la República Federal Alemana o $2^{\circ}$, a modificar el orden establecido en la Ley Fundamental, será castigado con pena de prisión, mínima de 10 años, o de cadena perpetua. 2. En casos de menor gravedad la pena de prisión será de 1 a 10 años.

También en los abusos sexuales a menores:

$\S 176$ b StGB (Abuso sexual a menor seguido de muerte): Si el autor causa por el abuso sexual ( $\S \S 176$ y 176 ) la muerte del niño -menor de 14 años-, como mínimo por imprudencia, entonces el castigo será de cadena perpetua o de privación de la libertad no inferior a 10 años.

En la violación:

§ 178 StGB (Coacción sexual y violación seguida de muerte): Si el autor causa por la coacción sexual o la violación (\$ 177) la muerte de la víctima, como mínimo por imprudencia, entonces el castigo será de cadena perpetua o de privación de la libertad no inferior a 10 años.

Y, en el robo:

$\S 251$ StGB (Robo seguido de muerte): Si el autor del robo (\$§ 249 y 250) causa la muerte de otra persona, como mínimo por imprudencia, entonces el castigo será de cadena perpetua o de privación de la libertad no inferior a 10 años.

En estas últimas conductas es necesario que ellas vayan acompañadas de muerte causada, al menos, por imprudencia. Sin embargo, tanto el Tribunal Constitucional -Bundesverfassungsgericht- (BVerfGE 50, 5; NStZ 94, 183) como el Tribunal Supremo -Bundesgerichtshof- (BGH NStZ-RR 99, 171) han mantenido la posibilidad de imponerla en los supuestos de tentativa y de culpabilidad disminuida, aunque solo cuando sea proporcionada a las circunstancias del caso, y se aplica tanto al autor como al cooperador necesario.

Por lo tanto, las muertes terroristas pueden constituir un delito de homicidio del § 212 StGB, y en este caso el juez decide facultativamente si impone cadena perpetua o prisión temporal. Pero, habitualmente, tendrán encaje en el § 211 StGB que regula el asesinato, puesto que esos hechos se suelen cometer por medios que entrañan un peligro público $y$, entonces, conllevan necesariamente cadena perpetua.

$\S 211$ StGB (Asesinato):

1. El asesino se castigará con cadena perpetua. 
2. Asesino es quien, por placer de matar, para satisfacer el instinto sexual, por codicia, o de otra manera por motivos bajos, con alevosía, o cruelmente, o con medios que constituyen un peligro público, o para facilitar otro hecho o para encubrirlo, mata a un ser humano.

§ 212 StGB (Homicidio):

1. Quien mata a una persona sin ser un asesino, será castigado como homicida con una pena privativa de libertad mínima de 5 años.

2. En casos especialmente graves cabe imponer cadena perpetua.

Por otra parte, el § 57a StGB regula la suspensión del resto de pena en la cadena perpetua:

§ 57 a StGB. Suspensión del resto de pena en la cadena perpetua:

(1) El tribunal suspenderá el resto de una pena de cadena perpetua, quedando el reo en libertad condicional cuando: 1. Se han cumplido 15 años de la pena, 2. La especial gravedad de la culpabilidad del condenado no haga necesario el resto de cumplimiento, y 3 . Se den los presupuestos del $\S 57$ párrafo 1 , frase $1, n^{\circ} 2$ y n $n^{\circ} 3$. Rige el $\S$ 57 párrafo 1 , frase 2 y párrafo 6 en lo pertinente.

(2) Como pena cumplida en el sentido del párrafo 1 frase $1 n^{\circ} 1$ rige toda privación de libertad que se haya impuesto al acusado con motivo del hecho.

(3) La duración del periodo de libertad condicional será de 5 años. El § 56 a párrafo 2 frase 1 y los $\S \S 56$ b a $56 \mathrm{~g}$ y el $\S 57$ párrafo 3, frase 2 y el párrafo 5 frase 2 rigen en lo pertinente.

(4) El tribunal puede fijar plazos máximos de 2 años, antes de cuyo vencimiento no se admite que el condenado presente una petición de que se le suspenda el resto de la pena.

Las remisiones efectuadas en el número 1 al § 57 StGB implican la exigencia de dos requisitos añadidos: que la suspensión "se pueda justificar teniendo en cuenta los intereses de la seguridad del público en general", y, que "la persona condenada consienta.

De acuerdo con esta norma, la condena se revisa siempre a los 15 años, sin que se contemplen periodos mayores, ni siquiera para los casos de concurrencia de delitos graves, como en el supuesto emblemático de múltiples asesinatos terroristas. De todas formas, en estos sucesos los elementos de juicio que han de valorarse para resolver la suspensión abocarán con absoluta certeza a la prolongación de la prisión, aunque difícilmente se alcancen los 35 años que fija el artículo 78 bis CP de forma ineludible para dichas situaciones.

En efecto, para decidir si se suspende la ejecución se tiene en cuenta la gravedad de la culpabilidad, que se valora a la vista del delito cometido y de la personalidad del autor. De acuerdo con la jurisprudencia, la culpabilidad tiene un peso especial -Schuldschwere-cuando el autor mata a varias personas, o si usa una especial brutalidad o ensañamiento con la víctima. Además, es condición para la suspensión que 'se pueda justificar teniendo en cuenta los intereses de la seguridad del público en general', es decir, se atiende a la peligrosidad del sujeto. Finalmente, es llamativo el último requisito, puesto que es necesario que 'el condenado dé su consentimiento a salir en libertad condicional'. De hecho, hay penados que optan por continuar en prisión, lo que revela que la reclusión puede tener un efecto tan 
deshumanizador que el interno no se sienta capaz de salir en libertad y de adaptarse a la vida social (Serrano \& Serrano, 2016).

Si se dan estos presupuestos, el Tribunal acuerda la suspensión de la pena y somete al condenado a condiciones durante un periodo de 5 años. En caso de no admitirla, podrá fijar un plazo máximo de 2 años durante el cual no cursará una nueva solicitud de libertad del penado.

Como se desprende de esta normativa, no se establecen reglas más estrictas, ni para supuestos de comisión de varios delitos graves, ni para los de terrorismo. En estos casos se puede prolongar la privación de libertad por encima de los 15 años, pero siempre conforme a los criterios generales señalados en el § 57a StGB. De todos modos, esos presupuestos legales incrementan notablemente las probabilidades de que el juez deniegue la suspensión, teniendo en cuenta que se valora la naturaleza del delito cometido y el peligro para la seguridad ciudadana, a la que se otorga prioridad absoluta, pues, sin duda, el supuesto que simboliza la mayor amenaza para esa seguridad pública actualmente lo constituye el fenómeno del terrorismo.

Recientemente, el tres de abril de 2017, el Tribunal Regional de Düsseldorf condenó a cadena perpetua al acusado que el diez de diciembre de 2012 puso una bomba en la estación central de Bonn, que no llegó a estallar al ser desactivada por la policía. En el juicio se alegó que era un artefacto falso porque no se halló ningún detonador. Pese a ello, el Tribunal estimó acreditado el intento de atentado y considera que la culpabilidad es elevada, por lo que excluyó la salida del condenado a los 15 años (Frankfurter Allgemeine, 2004).

Pues bien, la media de cumplimiento de la cadena perpetua en Alemania se sitúa en 19 años y en supuestos de extrema gravedad en 24 años, por debajo todavía del mínimo de 25 años que se prevé en nuestro derecho. Y esa diferencia se incrementa hasta 20 años cuando concurren delitos graves relacionados con el terrorismo, en los que la revisión no se hará antes de 28 o 35 años.

\section{Justificación del Tribunal Constitucional alemán por razones expiatorias.}

El Tribunal Constitucional alemán se pronunció sobre la cadena perpetua en la sentencia de 21 de junio de 1977. En concreto analizó la establecida con carácter obligatorio para el asesinato, puesto que el órgano judicial que planteó la cuestión entendía que podía ser contraria a la Ley Fundamental al no poder el juez analizar las circunstancias en cada caso para valorar la oportunidad de imponerla.

El Tribunal la declaró conforme a la Ley Fundamental, pero estableció requisitos importantes para que no vulnere la dignidad que el artículo 1 de esa norma declara inviolable: en primer término, destaca la necesidad de reconocer al penado una oportunidad concreta y realizable de recuperar su libertad y añade que, a estos efectos, no basta la vía del indulto:

El delincuente no puede ser considerado un mero objeto de la lucha contra el delito como pretexto para violar sus derechos y valores sociales constitucionalmente 
protegidos. Los presupuestos básicos de la existencia individual y social del hombre deben ser preservados. Del § 1 de la Ley Fundamental en relación con el principio del Estado social se deriva por ello -y esto es particularmente cierto para la prisión la obligación del Estado de conseguir que todos tengan una existencia conforme a la dignidad humana. Y sería incompatible con la dignidad humana así entendida que el Estado reclamara para sí a un hombre, privado de su libertad, sin darle al menos la oportunidad de poder obtener la libertad de nuevo (párrafo 145) [...] Al examinar la constitucionalidad de la cadena perpetua se ha indicado, en especial bajo referencia al $\S 1$ de la Ley Fundamental y al principio del Estado de Derecho, que una ejecución de la cadena perpetua que respete la dignidad humana sólo puede garantizarse si la persona condenada tiene una oportunidad concreta y realizable de poder recuperar más tarde la libertad; puesto que el núcleo de la dignidad humana se lesiona si el condenado, a pesar del desarrollo de su personalidad, debe renunciar a toda esperanza de recuperar su libertad. Bajo esta perspectiva, que permite que la ejecución de la cadena perpetua sea conciliable con la dignidad de la persona, de manera consistente con los requisitos constitucionales, no basta con el instituto del indulto (párrafo 191).

Además, declara que en la medida en que el condenado ha de poder alcanzar de nuevo su libertad, debe reconocérsele el derecho a la resocialización (Tribunal Constitucional alemán, 1977, sentencia, párrafo 177).

Por otra parte, el Tribunal analiza la cadena perpetua a la luz de los fines de la pena. En principio, rechaza su aplicación por motivos de prevención especial, dada la fragilidad de los pronósticos de peligrosidad, unida a los escasos índices de reincidencia en el asesinato:

El fin de la pena de la «prevención especial negativa» puede alcanzarse a través de la seguridad que supone internar al autor durante toda su vida. Pero saber si es necesario internar toda su vida al delincuente por razones de seguridad es algo que dependerá del riesgo de reincidencia. Este peligro es escaso, como se desprende de las estadísticas realizadas en el país (alrededor del $5 \%$ ), mientras que la tasa de reincidencia en delitos habituales es del 50 al 80 \%. Este hecho hace pensar a los miembros del Tribunal regional que una finalidad que busque la seguridad no es justificación suficiente, por sí misma, para imponer cadena perpetua a los autores de un asesinato. La condena de cualquier asesino, como regla general, a cadena perpetua supone, en todo caso, que la cantidad de pena y con ello la duración de la privación de libertad no depende, en principio, del resultado de un pronóstico criminal extremadamente difícil y, a menudo, también muy inseguro a largo plazo. Pero la opción contraria, de someterse a ese pronóstico, elevaría el riesgo, pues criminales violentos peligrosos podrían ser liberados tras pasar cierto tiempo en prisión, gracias a un pronóstico incorrecto (párrafos 220 y 221).

En cambio, señala que no se conculca el fin de reinserción social, puesto que se revisa siempre la condena a los 15 años, de manera que la permanencia en prisión depende de la peligrosidad, pero no es inherente a la cadena perpetua:

La imposición de la cadena perpetua, en la medida en que prevé legalmente la suspensión de la pena, no se contradice con la idea de resocialización que sustenta la Constitución ("prevención especial positiva"). El asesino condenado a cadena perpetua tiene básicamente la oportunidad de obtener de nuevo la libertad tras cumplir 
cierto tiempo de prisión... En todo caso, el objetivo de rehabilitación del sistema penal no puede llegar nunca a buen término respecto a un grupo de delincuentes, aquellos que siguen siendo peligrosos para la sociedad. Pero este peligro no se deduce de la condena a cadena perpetua, sino de las circunstancias particulares de la persona declarada culpable (párrafo 222).

Dice el Tribunal que, para el legislador, la pena cumple un fin expiatorio que justifica la aplicación de la cadena perpetua en delitos graves como el asesinato, es decir, responde a la pretensión de justicia de la sociedad:

Por último, nuestro sistema de sanciones penales admite como fines de la pena el dar una respuesta adecuada a la culpabilidad y también una expiación, y dado que el asesinato se sanciona por su extrema injusticia y elevada culpabilidad, la pena debe ser excepcionalmente alta. Esta pena también responde a la expectativa general de que se haga justicia. En consecuencia, el legislador amenaza a quien dispone de la vida de otro, cometiendo un asesinato, con la pena más alta que cabe. La función de la expiación de la pena es por ello fuertemente controvertida, en un momento en que la idea de la «defensa social» suscita un intenso debate. Si el legislador estima que la expiación es una finalidad legítima de la pena, puede deducirse que el asesino que arrebata una vida humana intencionadamente se arroga la culpabilidad más grave y su reintegración en la sociedad necesita una compensación de la misma, que es posible con una larga pena privativa de libertad que le permita la oportunidad de obtener la liberación (párrafos 223 y 224).

\section{La intensificación del castigo de las asociaciones terroristas tras el Otto- katalog.}

A raíz de los atentados del once de septiembre de 2001 en EEUU, el Gobierno federal alemán aprobó un grupo de medidas antiterroristas en el denominado Otto-Katalog -debido al entonces Ministro del Interior que adoptó las medidas, Otto Chily- que entró en vigor el primero de enero de 2002 -Gesetz zur Bekämpfung des Internationalen Terrorismus o Terrorismusbekämpfungsgesetz-, limitando las garantías de los ciudadanos especialmente en cuanto a la protección de los datos personales. Pero, también, reguló en el § 129a del Código Penal (StGB) -precepto modificado por la Ley de mejora del intercambio de información en la lucha contra el terrorismo internacional (BGBl. I p. 1818), de 26 de julio de 2016, que entró en vigor el 30 de julio del mismo año- el delito de creación de asociaciones terroristas, sancionando, entre otras, las constituidas con el objetivo de cometer asesinatos, homicidios, o genocidios, castigados con cadena perpetua (Portero, 2007).

§ 129 a. Creación de asociaciones terroristas.

1) Será castigado con pena privativa de libertad de uno a diez años quien funde una asociación, o participe en ella como miembro, cuyos objetivos o actividades se dirijan a cometer:

1. Asesinatos ( $\$ 211)$, u homicidios (\$ 212), o genocidios ( $\$ 6$ del Estatuto de la Corte Penal Internacional) o delitos contra la humanidad (\$ 7 del Estatuto de la Corte Penal Internacional) o delitos contra las leyes de la Guerra (\$§ 8, 9, 10, 11 o 12 del Estatuto de la Corte Penal Internacional).

2.- Delitos contra la libertad personal en los casos del § 239 a o del $\S 239$ b, o 
2).- Del mismo modo se castiga a quien funde una asociación, o participe en ella como miembro, cuyos objetivos o actividades se dirijan a cometer alguno de estos hechos: 1.- Infligir a otra persona grave daño físico o mental, especialmente de la clase especificada en el $\S 226$,

2.- Infracciones recogidas en $\S \S 303$ b, 305, 305a o delitos que tengan peligrosidad en los casos de $\S \S 306$ bis, 306c o 307, párr. 1 a 3, del $§ 308$, párr. 1 a 4, § 309, párr. 1 a 5, § § 313, 314 o 3151 , párr. 1, 3 o 4, § 316b párr. 1 o 3 o del § 316c párr. 1 a 3 o del § 317 párr. 1,

3.- Delitos contra el medio ambiente en los casos del § 330a Abs. 1 bis 3,

4.- Delitos conforme a § 19. párr. 1 a 3, § 20 párr. 1 o 2, § 20a. párr. 1 a 3, § 19 párr. $2, \mathrm{n}^{\circ} .2$, o párr. $3 \mathrm{n}^{\mathrm{o}} 2, \S 20$ párr. 1 o 2 o $\S 20$ a. párr. 1 a 3 , también en relación con el $\S$ 21 , o de acuerdo con $\$ 22$ a párr. 1 a 3 de la ley sobre el control de armas militares o 5.- Delitos según $\S 51$ párr. 1 a 3 de tenencia ilícita de armas.

Será preciso que cualquiera de los actos mencionados en los apartados 1 a 5 esté destinado a intimidar a la población de manera considerable, a coaccionar a una agencia gubernamental u organización internacional por la fuerza o a amenazar por el uso de fuerza a las estructuras políticas, constitucionales, económicas o sociales de un país o pretenda eliminar una organización internacional o afectar de manera significativa y dañar sustancialmente, por su naturaleza o sus efectos, un estado o una organización internacional.

3).- La pena privativa de libertad tendrá una extensión de seis meses a cinco años cuando la finalidad o actividad pretendida encaje en los delitos recogidos en el párrafo 1 y 2 antes indicados.

4).- De ser el autor cabecilla o instigador de la asociación, la pena privativa de libertad no será inferior a tres años, en los casos de los párrafos 1 y 2, y de uno a diez años, en los casos del párrafo 3.

5).- Quien apoye una asociación que pretenda cometer delitos de los apartados 1, 2 o 3, será castigado con pena privativa de libertad de seis meses a diez años, en el caso del apartado 3 la pena será de hasta cinco años de privación de libertad o de multa. Los que promuevan una asociación, con los fines de los apartados 1 o 2 serán castigados con prisión de seis meses a cinco años.

6).- El tribunal puede rebajar las penas cuando la culpa sea escasa y la colaboración del acusado tenga poca significación, en los casos previstos en los apartados 1, 2, 3 y 5, conforme a la discrecionalidad legal (\$ 49 párr. 2).

7).- El § 129 párrafo 6 rige en lo pertinente.

8).- Cuando la pena privativa de libertad tenga una extensión mínima de seis meses, el Tribunal tendrá la facultad de imponer la inhabilitación para ejercer toda función pública y los derechos de sufragio pasivo (§ 45 párr. 2).

9).- En los casos de los apartados 1, 2, 4 y 5 el Tribunal puede añadir una libertad vigilada (§ 68 párr. 1).

Al interpretar esta norma, el Tribunal Supremo ha requerido que la organización que opera en Alemania tenga cierta autonomía decisiva y organizativa. Así lo declaró la Sentencia 179/2010, de 28 de octubre de 2010 (BGH 3 StR 179/10, 2010):

Una sub-organización de una asociación extranjera que opera en Alemania sólo se considera independiente y nacional, a efectos de integrar los $\$ \S 129,129$ a StGB cuando cumple las condiciones personales, de organización, temporales y volitivas de esas normas. De ello se deduce que la agrupación parcial nacional tiene un grado suficiente de autonomía organizativa respecto de la organización extranjera (principal) cuando 
realiza el proceso de toma de decisiones, que vincula a sus miembros, de modo independiente. Por esto, no es suficiente con que los integrantes del subconjunto interno alcancen consenso para someterse a la voluntad de toda la organización; se requiere más bien que el proceso de toma de decisiones se lleve a cabo en su totalidad en la agrupación nacional.

Sin embargo, durante el proceso de ilegalización de la organización terrorista islámica 'Estado Califal' de Colonia, se introdujo el § 129b StGB, redactado por la Zehnten Zuständigkeitsanpassungsverordnung, de 31 de agosto de 2015 (BGBl. I S. 1474), que entró en vigor el 8 de septiembre del mismo año con el fin de luchar contra el terrorismo internacional de modo más eficaz (Ambos, 2007):

§ 129 b. Las asociaciones criminales y terroristas en el extranjero. Confiscación y decomiso ampliado.

1.- Los $\S \S 129$ y 129 a rigen también para asociaciones en el extranjero. A las asociaciones que se encuentren en países no miembros de la Unión Europea sólo se les aplicará cuando se cometan hechos comprendidos en el ámbito territorial de esta ley o cuando la víctima sea alemana o se encuentre en territorio nacional. En los casos de la segunda frase el hecho sólo será perseguido con autorización del Ministro de Justicia y para la protección del afectado. La autorización puede concederse para un caso individual o en general para la persecución de actos futuros cometidos por una asociación particular. Al decidir sobre la autorización, el Ministro valorará que los fines de la asociación ataquen los valores fundamentales del ordenamiento estatal que sustentan la dignidad del hombre o se dirijan contra la coexistencia pacífica de los pueblos y que esos fines parezcan reprobables, tras sopesar todas las circunstancias.

De modo novedoso, esta disposición amplía el ámbito punitivo y la competencia de los Tribunales penales alemanes a las asociaciones terroristas constituidas fuera de Alemania (Álvarez y González, 2006). De alguna manera, esta norma forma parte del derecho penal 'de la integración' que se ha abierto paso en Alemania en los últimos años, caracterizado por globalizar, no solo la economía y el conocimiento científico, sino también la pobreza, la delincuencia y el terrorismo, con la correspondiente respuesta penal (Velásquez, 2009).

Por otra parte, cabe apuntar que esa dureza legal y jurisprudencial contra los condenados por terrorismo, especialmente cuando han perpetrado o han intentado causar alguna muerte, también se extiende a la prisión preventiva, que se suele prolongar y se entiende justificada por la gravedad de esos hechos. Así, en la sentencia 21 de 14 de julio de 2016 (BGH StB 21/16, 2016), declaró proporcionada la privación de libertad durante un año y nueve meses, en virtud de los criterios marcados para la detención provisional en los delitos de terrorismo (sospecha de apoyo inminente a una organización terrorista extranjera, que se trate de un delito grave, y que haya riesgo de fuga).

\section{El internamiento indefinido en el Proyecto de ley de derechos del inmigrante (Zuwanderungsgesetz).}

Junto a las medidas adoptadas en el llamado Otto-Katalog, el ministro Schily pretendió introducir en la nueva ley de inmigración que se estaba tramitando un 
régimen de internamiento de seguridad de carácter indefinido, sin juicio previo, para sospechosos de terrorismo que no pudieran ser extraditados. Para ello, bastaba la sospecha de que un individuo tenía contactos con organizaciones terroristas internacionales. En la comisión interparlamentaria creada para negociar el contenido del nuevo texto se rechazó ese capítulo, pero hubo consenso sobre la posibilidad de extraditar a un sospechoso o, en caso de no ser posible, someterlo a régimen de internamiento a partir de un pronóstico de peligrosidad. En concreto, esas decisiones se podrían adoptar cuando existan sospechas de que una persona ha estado en un campo de entrenamiento de la red terrorista $A l$ Qaeda, que ha luchado en Chechenia o que ha distribuido vídeos de la yihad islámica.

Finalmente, se aprobó la Ley de derechos del inmigrante (Zuwanderungsgesetz), basada en el Proyecto de tres de agosto de 2001 del ministro Otto Schily, que entró en vigor el primero de enero de 2005, bajo el título Gesetz zur Steuerung und Begrenzung der Zuwanderung und zur Regelung des Aufenthalts und der Integration von Unionsbürgern und Ausländern, modificada después por las leyes de 28 de marzo de 2007 y 27 de abril de 2012, a fin de adaptarla a la normativa europea. En esta disposición se establecieron numerosas medidas de control y seguridad respecto de los extranjeros -llaman la atención algunas disposiciones como la expulsión obligatoria del extranjero condenado por tráfico de drogas (\$ 53.2), y la expulsión facultativa si "abusa de drogas peligrosas como cocaína y heroína, sin hacer esfuerzos de rehabilitación [...] pone en peligro con su conducta la salud pública [...]" (\$ 55.2)-, pero no se incluyó el polémico internamiento indefinido, que resultaba contrario a los principios consagrados en la Ley Fundamental (Grundgesetz) y, particularmente, a la dignidad proclamada en el artículo 1. En la redacción final se contempló tan solo el internamiento a efectos de garantizar la orden de expulsión:

§ 55. Expulsión por regla general: un extranjero será expulsado por regla general cuando: [...] 5.- existan indicios que lleven a concluir que pertenece o ha pertenecido a alguna asociación que apoya el terrorismo o apoya o ha apoyado una asociación de ese tipo, y si perteneció o la apoyó en el pasado, la expulsión podrá justificarse si existen razones de peligro en el presente.

Ello, de forma similar a la prevista en España y en otros ordenamientos europeos y se dejaba fuera una medida que recordaba a Guantánamo; en efecto:

§ 54A. Vigilancia de ciertos extranjeros por razones de seguridad interior:

1).- Un extranjero contra el que se emite una orden de expulsión por infringir el apartado $5^{\circ}$ o el $5^{\circ} \mathrm{A}$ del $\S 54$ o una orden de deportación del $\S 58 \mathrm{~A}$ quedará sometido a la obligación de comparecer, al menos una vez por semana, en el retén policial más cercano a su domicilio, hasta que la autoridad de extranjería no resuelva lo contrario. Si la orden de expulsión iniciada se motiva en otra causa, podrá acordarse esa obligación de comparecencia si se motiva por razones de seguridad o de orden público.

2).- Su residencia estará limitada al distrito de la autoridad de extranjería, hasta que la autoridad de extranjería no resuelva lo contrario.

3).- Podrá ser obligado a vivir en otro lugar o en determinados alojamientos, incluso fuera del distrito de la autoridad de extranjería, cuando esto sea necesario, para ejecutar la orden de expulsión, impedir o prevenir su incumplimiento, y poder también 
así supervisar el cumplimiento de las órdenes e instrucciones legales que se hayan impuesto.

4).- Para lograr su identificación, los extranjeros podrán ser sometidos a medidas de control de sus comunicaciones [...]

5).- Las disposiciones de los apartados 1 a 4 quedan suspendidas si el extranjero se encuentra preso. Las disposiciones de los apartados 3 y 4 son ejecutivas inmediatamente.

\section{Conclusiones}

El derecho alemán ha tenido una clara influencia en la normativa de la prisión permanente revisable. De hecho, se regula esencialmente su suspensión y se establecen criterios para efectuar el pronóstico de peligrosidad similares a los enumerados en el § 56 StGB para la suspensión de la pena de prisión. Por eso, teniendo en cuenta que Alemania sufre en general unos índices mayores de delincuencia (Ussía, 2017), la atención al régimen de la cadena perpetua previsto en ese país puede servir como referente para valorar si están o no justificadas las condiciones excepcionalmente rigurosas establecidas para la nueva pena en los delitos relacionados con el terrorismo, especialmente si existe concurrencia delictiva.

Pues bien, cabe afirmar que, en general, la normativa sobre la suspensión es más beneficiosa en la legislación germana. La revisión se efectúa siempre a los 15 años y lo normal es que se excarcele al penado, salvo en casos particularmente graves. La media de cumplimiento es de 19 años y de 24 años en hechos de extrema entidad. Este tiempo no llega siquiera al término de 25 años previsto para la prisión permanente revisable con carácter general en España y mucho menos a los 35 años señalados en el artículo 78 bis CP para los casos de concurrencia de delitos graves relacionados con el terrorismo.

Ahora bien, en Alemania la cadena perpetua se aplica cuando el delito queda en grado de tentativa y no solo a los autores, sino, también, a los partícipes, mientras que, en nuestro sistema, cualquier causa que determina la rebaja de la pena en grado, sea por tentativa, complicidad, concurrencia de atenuantes, de una muy cualificada, o de una eximente incompleta, supone la exclusión de la prisión permanente y la aplicación de una pena de prisión, aunque considerablemente elevada, pues oscila entre 20 y 30 años.

De todos modos, el contraste entre ambos ordenamientos lleva a concluir que la prevención y la tutela de los bienes cubiertos por la prisión permanente no justifican dos regímenes de tan dispares en cuanto al tiempo de privación efectiva de libertad.

Por otra parte, en el Código Penal español se han introducido normas de naturaleza penitenciaria que no figuran en el texto punitivo alemán, lo que ha dado lugar a una regulación dispersa totalmente inadecuada desde el punto de vista de la seguridad jurídica (Redondo, 2009; Asencio, 2010; Boldó, 2013; Cervelló, 2015).

En suma, la prisión permanente revisable adolece de un rigor excesivo, atendiendo al volumen de delincuencia en nuestro país y específicamente al porcentaje de 
asesinatos, que es el principal delito sancionado con esta pena. Esta severidad lleva a poner en tela de juicio la adecuación de esta nueva sanción a los principios constitucionales, particularmente los de proporcionalidad y resocialización. Las críticas se centran en la normativa excepcional introducida para los delitos relacionados con el terrorismo y la delincuencia organizada. Además, la incorporación al Código Penal de previsiones penitenciarias específicas, que afectan sobre todo a estas formas de criminalidad, ha dado lugar a un régimen contrario al principio de certeza.

En definitiva, bajo el paraguas de las garantías constitucionales y singularmente del principio de resocialización del artículo 25.2 CE el legislador ha tratado de legitimar un régimen mucho más estricto que el alemán, donde el Tribunal Constitucional ha declarado abiertamente que la cadena perpetua cumple un fin expiatorio y a partir de esta constatación es mucho más exigente en cuanto a las condiciones que han de observarse para que la prisión indefinida sea conforme a la dignidad garantizada en la Ley Fundamental. Es decir, en la ley de reforma se ha hecho un uso artificioso del fin resocializador para justificar una limitación desproporcionada de la libertad, proclamada como valor superior de nuestro ordenamiento jurídico, olvidando además la dignidad de la persona amparada también en el texto constitucional.

\section{Referencias}

Abel, M. (2015a). Life imprisonment: criminal penalty theories and its practice in a global era. Seventh Session of the International Forum on Crime and Criminal Law in the Global Era. Beijing. Recuperado de https://www.unodc.org/ngo/ showSingleDetailed.do?req_org_uid=23477).

Abel, M. (2015b). Cadena perpetua y delitos contra la comunidad internacional (arts. 605.1, 607 y 607 bis). En J. L. González (Dir.), Comentarios a la Reforma del Código Penal de 2015 (2 ed.) (pp. 1355-1374). Valencia: Tirant lo Blanch.

Acale, M. (2016). La prisión permanente revisable: ¿Pena o cadalso? Madrid: Iustel.

Acale, M. (2013). En F. J. Álvarez (Dir.) y J. Dopico (Coord.), Estudio crítico sobre el anteproyecto de reforma penal de 2012 (pp. 179-200). Valencia: Tirant lo Blanch.

Álvarez, E. y González, H. (2006). Legislación antiterrorista comparada después de los atentados del 11 de septiembre y su incidencia en el ejercicio de los derechos fundamentales. Real Instituto Elcano, ARI (7). Recuperado de http://www. realinstitutoelcano.org.

Álvarez, F. J. (2014). La nueva reforma penal de 2013. Eunomía. Revista en Cultura de la Legalidad (6), pp. 14 y ss.

Ambos. K. (2007). El Derecho penal frente a amenazas extremas. Madrid: Dykinson.

Asencio, J. (2010). Cadena perpetua revisable. Una medida dudosamente constitucional. Práctica de Tribunales (70), 3-5. 
Boldó, G. (junio, 2013). Prisión permanente revisable y falta de seguridad jurídica. Diariojurídico. Recuperado de http/ / www.diariojuridico.com.

Bonet, M. (marzo, 2015). 8 razones por las que la reforma del Código penal recorta las garantías de la ciudadanía (26). Recuperado de http/ / www.eldiario.es.

BGH 3 StR 179/10, Urteil vom 28. (Oktober 2010) -OLG Frankfurt am Main-. Recuperado de https: / / dejure.org

BGH StB 21/16 - 14. Juli 2016 -OLG Stuttgart- [= HRRS 2016 Nr. 782]. Recuperado de https:/ / dejure.org

Cámara, S. \& Fernández, D. (2016). La prisión permanente revisable: el Ocaso del Humanitarismo Penal y Penitenciario. Pamplona: Aranzadi.

Cancio, M. (2013). La pena de cadena perpetua («prisión permanente revisable») en el Proyecto de reforma del Código penal. Diario La Ley (8175), Recuperado de http / / diariolaley.laley.es.

Cano, M. (2015). Los delitos de violencia doméstica y en el ámbito familiar o asimilado y los de trata de seres humanos. En L. Morillas (Dir.), Estudios sobre el Código penal reformado (pp. 917-923). Madrid: Dykinson.

Carbonell, J. (2015). Prisión permanente revisable I (arts. 33 y 35). En J. L. González (Dir.), Comentarios a la Reforma del Código Penal de 2015 (2 ed.) (pp. 211-222). Valencia: Tirant lo Blanch.

Caso Stafford vs. United Kingdom. (2002, mayo 28). Sentencia. Tribunal Europeo de Derechos Humanos. Recuperado de http:/ / www.echr.coe.int/Pages/home. aspx?p=home

Caso R. vs. Bieber (2008, julio 23). Court of Appeal (Criminal Division). Recuperado de file:// /D:/368_201042_95337.pdf

Caso R. vs. David Oakes and Others (2012, noviembre 21). Royal Courts of Justice, London. Recuperado de https: / / www.judiciary.gov.uk/wp-content/uploads / JCO/Documents/Judgments/r-v-david-oakes-and-others.pdf

Caso Vinter vs. United Kingdom (2013, julio 9). Sentencia. Tribunal Europeo de Derechos Humanos. Recuperado de http://www.echr.coe.int/Pages/home. aspx?p=home

Caso Vinter vs. United Kingdom (2014, febrero 18). Sentencia. Tribunal Europeo de Derechos Humanos. Recuperado de http:/ / www.echr.coe.int/Pages/home. aspx?p=home

Caso Hutchinson vs. United Kingdom (2015, febrero 3). Tribunal Europeo de Derechos Humanos. Recuperado de http://www.echr.coe.int/Pages/home. aspx?p=home 
Caso Hutchinson vs United Kingdom (2017, enero 17). Tribunal Europeo de Derechos Humanos. Recuperado de http://www.echr.coe.int/Pages/home. aspx?p=home

Castellví, C. (2015a). Terrorismo. En M. Corcoy (Dir.), Manual de Derecho penal. Parte especial (T. I) (pp. 768-782). Valencia: Tirant lo Blanch.

Castellví, C. (2015b). De los delitos de terrorismo. En M. Corcoy y S. Mir (Dirs.), Comentarios al Código penal (pp. 1734-1736). Valencia: Tirant lo Blanch.

Cervelló, V. (2015a). Prisión perpetua y de larga duración. Valencia: Tirant lo Blanch.

Cervelló, V. (2015b). Prisión permanente revisable II (art. 36). En J. L. González (Dir.), Comentarios a la Reforma del Código Penal de 2015 (2 ed.) (pp. 737-782). Valencia: Tirant lo Blanch.

Consejo Fiscal. (2012). Informe al Anteproyecto de Ley Orgánica por la que se modifica la Ley Orgánica 10/1995.

Consejo General del Poder Judicial. (2013). Informe al Anteproyecto de Ley Orgánica por la que se modifica la Ley Orgánica 10/1995, de 23 de noviembre, del Código Penal.

Cuello, J. y Mapelli, B. (2015). Curso de Derecho penal. Parte general (3 ed.). Madrid: Tecnos.

Cuerda, M. L. (2016). En Vives, T. S. et al. (Autores) \& J. L. González (Coord.), Derecho penal. Parte especial, 5 ed. (pp. 767 y 768). Valencia: Tirant lo Blanch.

Cuerda, A. (2011). La cadena perpetua y las penas muy largas de prisión: por qué son inconstitucionales en España. Barcelona: Atelier.

Cuerda, A. (2012). Inconstitucionalidad de la prisión permanente revisable y de las penas muy largas de prisión. Otrosí (12), 29-33.

Daunis, A. (2013). La prisión permanente revisable. Principales argumentos en contra de su incorporación al acervo punitivo español. Revista de Derecho Penal y Criminología (10), 65-114.

De la Cuesta, J. L. (2009). El principio de humanidad en el Derecho penal. Eguzkilore (23), 209-225.

Del Carpio, J. (2013). La pena de prisión permanente en el Anteproyecto de 2012 de reforma del Código penal (1). Diario La Ley (8004). Recuperado de http/ / diariolaley.laley.es.

Díaz-Maroto y Villarejo, J. (2012). El afán de reformar. Revista Jurídica de la Universidad Autónoma de Madrid (25), 11-16.

Díez-Ripollés, J. (2006). Algunos rasgos de la delincuencia en España a comienzos del siglo XXI. Revista Española de Investigación Criminológica, Artículo 1 (4), 1-19. 
Díez-Ripollés, J. (24 de febrero de 2015). La pena de prisión permanente revisable es una cadena perpetua, y de las más duras. Recuperado de http:/ / www.eldiario.es / andalucia/Jose-Luis-Ripolles-Derecho-Penal_0_360114085.html

Díez-Ripollés, J. (2013). Sucintas observaciones sobre algunas decisiones del Anteproyecto de reforma del Código penal de 2012. En F. Álvarez (Dir.) y J. Dopico (Coord.), Estudio crítico sobre el Anteproyecto de reforma penal de 2012 (p. 49-66). Valencia: Tirant lo Blanch.

Fernández, D. (2014). Una propuesta revisable. La Ley Penal (110), 75-87.

Fernández, J. (2014). Las penas privativas de libertad en la reforma de Gallardón: especial referencia a la prisión permanente revisable. En A. Pérez (Dir.) y M. Gorjón (Coord.), El Proyecto de reforma del Código penal de 2013, a debate (pp. 4973). Madrid: Dykinson.

Fischer, T. (2012). Strafgesetzbuch und Nebengesetze (59 Edición) (pp. 323 y ss.). München: C. H. Beck.

Fischer, T. (2015). Höchststrafe Schafft Lebenslang ab! Zeit on line. Recuperado de http://www.zeit.de/gesellschaft/zeitgeschehen/2015-02/lebenslangefreiheitsstrafe-schuld).

„Frachtpreise“ bringen Moeller-Maersk-Aktie kaum noch weiter. (26 de marzo de 2004). Frankfurter Allgemeine. Recuperado de http://www.faz.net/aktuell/ finanzen/aktien/konglomerate-frachtpreise-bringen-moeller-maersk-aktiekaum-noch-weiter-1141625.html

Fuentes, J. (2014). ¿La botella medio llena o medio vacía? La prisión permanente revisable: el modelo vigente y la propuesta de reforma. Revista de Derecho Constitucional Europeo (21). Recuperado de http:/ / www.ugr.es.

García R. (2016). Art. 564. En G. Quintero (Dir.) y F. Morales (Coord.), Comentarios al Código penal español, Tomo II. Pamplona: Aranzadi.

García, E. y Díez-Ripollés, J. (2013): La Administración de justicia según los datos. Málaga: Instituto Andaluz Interuniversitario de Criminología.

García, E.; Díez-Ripollés, J.; Pérez, F.; Benítez M. y Cerezo, A. (2010). Evolución de la delincuencia en España: análisis longitudinal con encuestas de victimización. Revista Española de Investigación Criminológica, Artículo 2 (8), 1-27.

García, N. (2014). El Proyecto de reforma del Código penal de 2013 como programa inocuizador de delincuentes peligrosos (Prisión permanente revisable y medidas de seguridad indeterminadas). Diritto Penale Contemporaneo (3-4), 178-199.

García, C. (septiembre, 2012). El doble flujo de la legislación penal y sus límites: la cadena perpetua. Diario Cuartopoder. Recuperado de http/ / www.cuartopoder.es.

Gobierno de España (2015). Informes. Recuperado de http:/ / www.interior.gob.es / prensa/balances-e-informes/2015 
González, M. (2013). Prisión perpetua: Arts. 36 (3 y 4), 70, 76 y 78 bis CP. En F. J. Álvarez (Dir.) y J. Dopico (Coord.), Estudio crítico sobre el Anteproyecto de reforma penal de 2012 (pp. 205-222). Valencia: Tirant lo Blanch.

Grupo de estudios de política criminal (febrero, 2015). No hay derecho. Por un Código penal de todos. Comunicado ante la reforma del Código penal. Recuperado de http:/ / www.gepc.es/web.

Hidalgo, S. (2013). Comentario jurídico-social sobre la modificación del Código penal. La prisión permanece revisable en España. Revista General de Derecho Penal (19). Recuperado de http:/ / www.iustel.com.

Jaén, M. (2013). Prisión permanente revisable. El Cronista del Estado Social y Democrático (35), 44-50.

Jaén, M. y Perrino, A. (2015). La Reforma penal de 2015. Madrid: Dykinson.

Juanatey, C. (2012). Política criminal, reinserción y prisión permanente revisable. Anuario de Derecho Penal y Ciencias Penales (LXV), 127-153.

Juanatey, C. (2013). Una «moderna barbarie»: la prisión permanente revisable. Revista General de Derecho Penal (20). Recuperado de http:/ / www.iustel.com.

Juanatey, C. (2016). Manual de Derecho penitenciario. Madrid: Iustel.

Külhl, K. (2011). Strafgesetzbuch Kommentar (27 Auflage). München: C. H. Beck.

Lamarca, C. (2016). Delitos contra el orden público. En C. Lamarca (Coord.), Delitos. La parte especial del Derecho penal (pp. 993-994). Madrid: Dykinson.

Landa, J. (2015). Prisión perpetua y de muy larga duración tras la LO 1/2015: ¿derecho a la esperanza? Con especial consideración del terrorismo y del TEDH. Revista Electrónica de Ciencia Penal y Criminología (17-20), 1-42.

Lascuraín, J.A. (2015). Carta a los Senadores: protéjannos de la pena. Claves de razón práctica (239), 66-75.

Manzanares, J. (2015). La reforma del Código penal de 2015. Conforme a las Leyes Orgánicas 1 y 2/2015, de 30 de marzo. Madrid: La Ley.

Marín de Espinosa y Ceballos, E. B. y González, M. (2013). Prisión perpetua (Art. 36.3 y 4 CP). En F. J. Álvarez (Dir.) y J. Dopico (Coord.), Estudio crítico sobre el Anteproyecto de reforma penal de 2012 (pp. 201-204). Valencia: Tirant lo Blanch.

Martín, J. (2012). Inconstitucionalidad de la cadena perpetua. Actualidad Jurídica Aranzadi (854), 6.

Mir, S.; Gómez, V. y Valiente, V. (2015). Derecho penal. Parte general (10 ed.). Barcelona: Reppertor. 
Muñoz, F. (2012). Algunas reflexiones sobre la pena de prisión perpetua y otras sanciones similares a ella. Teoría y derecho: Revista de pensamiento jurídico (11), 250-273.

Muñoz, F. (2015). Derecho penal. Parte especial (20 ed.) Valencia: Tirant lo Blanch.

Muñoz, F. y García, M. (2015). Derecho penal. Parte general (9 ed.) Valencia: Tirant lo Blanch.

Nistal, J. (2010). ¿Es viable en nuestro ordenamiento jurídico la pena de «cadena perpetua» como solución para determinado tipo de delincuentes difícilmente reinsertables? La Ley Penal (68), 2.

Olmedo, M. (2016). De las organizaciones y grupos terroristas. Delitos de terrorismo. En Morillas (Dir.), Sistema de Derecho penal. Parte especial (pp. 14231426). Madrid: Dykinson.

Orts, E. y González, J. L. (2016). Compendio de Derecho penal. Parte general (6 ed.). Valencia: Tirant lo Blanch.

Ortiz, I. (2012). El Tribunal Constitucional tiene las manos atadas frente a la prisión permanente revisable. Iuris: Actualidad y Práctica del Derecho (176), 8.

Portero, M. (2007). Regulación penal del terrorismo en los países miembros de la Unión Europea. Recuperado de https: / /investigacion.uclm.es.

Queralt, J. (2015). Derecho penal español. Valencia: Tirant lo Blanch.

Reino de España. Ministerio de Justicia. (2012). Anteproyecto de Ley Orgánica por la que se modifica la Ley Orgánica 10/1995, de 23 de noviembre, del Código Penal. Recuperado de http://www.juecesdemocracia.es/ActualidadMJU/2012/ Anteproyecto\%20de\%20reforma\%20de\%20CP\%202012.pdf

Reino de España. Consejo de Estado. (junio, 2013) Dictamen sobre el Anteproyecto de ley orgánica por la que se modifica la Ley Orgánica 10/1995, de 23 de noviembre, del Código Penal, de 27 de junio de 2013 (Consideración séptima).

Reino de España. Ley Orgánica 1 de 2015. Por la que se modifica la Ley Orgánica 10/1995, de 23 de noviembre, del Código Penal. BOE No. A-2015-3439. Congreso de los Diputados, marzo de 2015.

Reino de España. Ley Orgánica 2 de 2015. Por la que se modifica la Ley Orgánica 10/1995, de 23 de noviembre, del Código Penal, en materia de delitos de terrorismo. BOE No. A-2015-3440. Congreso de los Diputados, marzo de 2015.

Reino de España. (marzo, 2015). Boletín Oficial de las Cortes Generales, Senado, X Legislatura.

Reino de España. (2015). Diario de Sesiones del Congreso de los Diputados, Pleno y Diputación Permanente, año 2015, X Legislatura, n. ${ }^{\circ}$ 69, Sesión Plenaria, n. 252. 
Ramírez, J. y Rodríguez, J. (2013). Fin de trayecto: custodia de seguridad, libertad vigilada y prisión permanente revisable, en el Anteproyecto de reforma del Código penal. Jueces para la Democracia (76), 50-80.

Redondo, A. (2009). La cadena perpetua en el Derecho español. La Ley Penal (62), 4.

Ríos, J. (2013). La prisión perpetua en España. Razones de su ilegitimidad ética y de su inconstitucionalidad. Revista de Derecho Penal y Criminología (Extra), 177212.

Ríos, J. (2014). La pena de prisión permanente revisable. Razones de su inconstitucionalidad. En M. Valle Mariscal de Gante (Coord.), La reforma penal de 2013: Libro de Actas. Jornadas de profesores y estudiantes de Derecho penal de las Universidades de Madrid (pp. 21-62). Madrid: Universidad Complutense de Madrid.

Roig, M. (2013). La cadena perpetua: los modelos inglés y alemán. Análisis de la STEDH de 9 de julio de 2013. La "prisión permanente revisable» a examen. Cuadernos de Política Criminal (111), 97-144.

Roig, M. (2014). La suspensión de la pena en el Proyecto de reforma del Código penal. Un giro hacia el Derecho penal de autor. Revista Penal (33), 170-207.

Roig, M. (2016). La cadena perpetua en el Derecho alemán y británico. La prisión permanente revisable. Madrid: Iustel.

Rueda, M. (2016). En C. Romeo, E. Sola y M. Á. Boldova (Coords.), Derecho penal. Parte especial (pp. 828 y ss.). Granada: Comares.

Sáez, C. (2013). Comentarios acerca del sistema de penas en la proyectada reforma del Código penal español. InDret. Recuperado de http/ / www.indret.com.

Sanz, N. (2012). De las libertades del Marqués de Beccaria, al todo vale de Günter Jakobs. Revista Electrónica de Ciencia Penal y Criminología (14-10), 1-29. Recuperado de http//www.criminet.ugr.es/recpc.

Sanz, N. (2016). La pena privativa de la libertad y sus alternativas. En I. Berdugo (Coord.), Lecciones y materiales para el estudio del Derecho penal. Tomo VI. Derecho penitenciario (2 ed.) (pp. 13-38). Madrid: Iustel.

Sentencia 43 (1986, abril 15). Tribunal Constitucional.

Sentencia 32 (2003, febrero 13). Tribunal Constitucional.

Sentencia 148 (2004, septiembre 13). Tribunal Constitucional.

Sentencia 181 (2004, noviembre 2). Tribunal Constitucional.

Sentencia 135 (2006, diciembre 11). Tribunal Constitucional.

Sentencia. (1977, junio 21). Az. 1 BvL 14/76. Tribunal Constitucional alemán. 
Serrano, A. (2013). Notas al Anteproyecto de reforma del Código penal español de octubre de 2012. Revista Electrónica de Ciencia Penal y Criminología (15). Recuperado de http/ / criminet.ugr.es.

Serrano, A. (2014). La «Prisión Permanente Revisable» en el Anteproyecto de Reforma del Código Penal Español. En A. Ferreira; A. Serrano y S. Marlice (Coords.), Estudos de Direito Penal, Processual e Criminologia em Homenagem ao Prof. Dr. Kurt Madlener, Conselho da Justiça Federal. Brasilia: Centro de Estudos Judiciários.

Serrano, A. y Serrano, I. (2016). Constitucionalidad de la prisión permanente revisable y razones para su derogación. Madrid: Dykinson.

Serrano, M. (2012). La prisión permanente revisable. Revista Jurídica Universidad Autónoma de Madrid (25), 167-187.

Stree, W. y Kinzig, J. (2006). En A. Schönke y H. Schröder, Strafgesetzbuch Kommentar (27 Auflage). München: C. H. Beck.

Tamarit, J. (2015). La prisión permanente revisable. En G. Quintero (Dir.), Comentario a la reforma penal de 2015 (pp. 93-100). Pamplona: Aranzadi.

Terradillos, J. (2012). La reforma española de 2012. Líneas maestras. Revista Nuevo Foro Penal 7(78), 13-31.

Tröndle, H. y Fischer, T. (2006). Beck'sche Kurz Kommentare. Band 10. München: C. H. Beck.

Unión Europea (2015). La criminalidad desciende un 3,6\% en 2014 y posiciona a España entre los países más seguros del mundo. En Gobierno de España. Recuperado de http://www.interior.gob.es/prensa/noticias/-/asset_publisher/ GHU8Ap6ztgsg/content/id/3283275

Urruela, A. (2012). La cadena perpetua revisable en la legislación española desde la perspectiva del Derecho penal. Actualidad Jurídica Aranzadi (838), 9.

Usía, A. (20 de septiembre de 2017). España, tercer país europeo con la tasa de criminalidad más baja. La razón.es. Recuperado de http://www.larazon.es / espana / espana-tercer-pais-europeo-con-la-tasa-de-criminalidad-mas-bajaFA10762632\#.Ttt1g2FNRVv4AMa

Vázquez, C. (2015). Código penal comentado. Barcelona: Atelier.

Velásquez, F. (2009). Del Derecho penal funcionalista al Derecho penal de la integración. Cuadernos de Derecho Penal (1). Recuperado de http://revistas. usergioarboleda.edu.co/index.php/cuadernos_de_derecho_penal/article/ viewFile/360/304. 